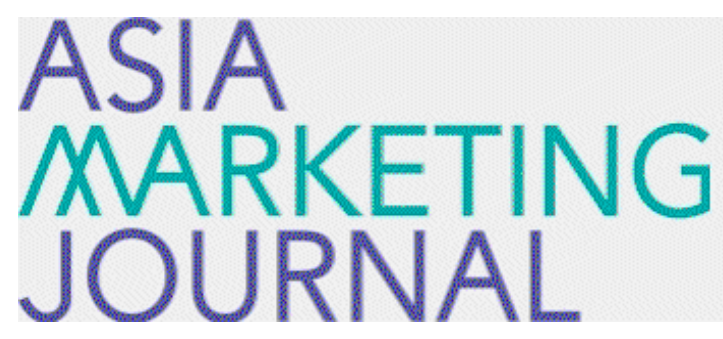

ASIA MARKETING JOURNAL

Volume 14 | Issue 4

Article 6

$1-30-2013$

\title{
How AMOREPACIFIC Became a Globally Successful Cosmetic Company through Unconventional but Sensational Marketing?
}

Chung K Kim

Jeong Soo Han

Mina Jun

Kim

Joshua Y Kim

Follow this and additional works at: https://amj.kma.re.kr/journal

Part of the Marketing Commons

\section{Recommended Citation}

Kim, Chung K; Han, Jeong Soo; Jun, Mina; Kim; and Kim, Joshua Y (2013) "How AMOREPACIFIC Became a Globally Successful Cosmetic Company through Unconventional but Sensational Marketing?," Asia Marketing Journal: Vol. 14 : Iss. 4 , Article 6.

Available at: https://doi.org/10.53728/2765-6500.1502

This Article is brought to you for free and open access by Asia Marketing Journal. It has been accepted for inclusion in Asia Marketing Journal by an authorized editor of Asia Marketing Journal. 


\title{
How AMOREPACIFIC Became a Globally Successful Cosmetic Company through Unconventional but Sensational Marketing?*
}

\author{
Chung K. Kim** \\ Jeongsoo Han*** \\ Mina Jun**** \\ Miyea Kim* \\ Joshua Y. Kim*
}

AMOREPACIFIC has rapidly grown to become a successful global brand by persistently seeking and achieving success in foreign markets. In 2011, AMOREPACIFIC was ranked as one of the global top 20 cosmetics companies.

What makes AMOREPACIFIC's global success noteworthy is that AMOREPACIFIC challenged the Franœe and the US market, where competition level is the toughest. Lolita Lempicka, AMOREPACIFIC's perfume brand, was chosen as one of the top seven most popular brands in the women's perfume market in France. In addition, Amorepacific, AMOREPACIFIC's namesake skincare brand, is currently recognized as a top prestige brand in the USA. Their success played a significant role as a bridgehead for AMOREPACIFIC in becoming a global cosmetics company.

The main object of this case study is to analyze how AMOREPACIFIC became a global cosmetic company through building key brands such as Lolita Lempicka and Amorepafic, among others. Therefore, this study reviewed AMOREPACIFIC's unconventional approach in launching Lolita Lempicka in France, and Amorepacific in the US by focusing on how they foresaw the future opportunities and employed innovative marketing strategies. Specifically, we focused on Amorepacific's marketing strategy under the critical period when AMOREPACIFIC achieved great success in France with Lolita Lempicka (between 1997 and 2004) and in US with the brand, Amorepacific (2003-2008).

The case of AMOREPACIFIC's success in the global markets can give valuable lessons to companies

\footnotetext{
* We would like to thank anonymous people of Amorepacific for their comments and sharing the data.

** Professor, Graduate School of Business, Sungkyunkwan University(kimkim@skku.edu)

*** Doctoral Candidate, Graduate School of Business, Sungkyunkwan University(j3916@gmail.com), corresponding author

**** Doctoral Candidate, Graduate School of Business, Sungkyunkwan University(alskwjs@skku.edu)

***** Doctoral Candidate. Graduate School of Business, Sungkyunkwan University(cally0615@skku.edu)

****** Fulbright Scholar, College of Human Ecology, Seoul National University(jyk42@cornell.edu)
} 
that want to extend their businesses to foreign countries and ultimately become global. One such lesson is the importance of building a successful pioneer brand in a powerful bridgehead market. While domestic competitors first entered into less competitive markets such as those in South-East Asia. AMOREPACIFIC challenged the toughest markets such as the French and US markets where the incumbent companies waged the most intensive and severe battles against Lolita Lempick and Amorepacific. Through the success in France and US market, however, AMOREPACIFIC built a powerful base for its successful global expansion.

Another valuable lesson is the importance of foresight in uncovering great opportunities hidden behind the trends without losing focus on the brand's core character and values. Lolita Lempicka and Amorepacific showed excellence in foresight competition, which led them to succeed against the intense competition from Goliath companies. If Lolita Lempicka and Amorepacific had just followed the popular market trend at the time, they would have never succeeded.

Key words: Foresight, Global Strategy, AMOREPACIFIC, Brand Amorepacific, Lolita Lempicka, Korean Brands.

\section{Introduction to the Case Study}

A recent global survey shows that Chanel No.5, Dior J'Adore, Lolita Lempicka, Kenzo Flower, Yves Saint Laurent, Nina Ricci and Thierry are the top seven most popular brands in the women's perfume market in France (meuilleur-top.com, 2012). For many, it is very surprising to discover that Lolita Lempicka is actually a Korean brand created by the Korean cosmetic company AMOREPACIFIC. How could that happen? How could a Korean company, which was not that well-known globally, create a top global brand widely popular even in France, the Mecca of cosmetic products?

AMOREPACIFIC's success is not limited to
France. Its other brand, AP (or Amorepacific) is currently recognized as a top prestige brand in the USA. Many of its products are understood to not only cleanse, but also to nurture healthy skin. How could AMOREPACIFIC, a small company unknown to the global market, achieve top performance in competitive markets in France and the USA and earn such global recognition?

"To become a global leading company that creates the harmonious value of health and beauty" has always been AMOREPACIFIC's vision and dream. The company has kept on moving forward to share the value of Korean beauty with the world as its title, "Asian Beauty Creator," suggests. The vision and dream has come true since AMOREPACIFIC has rapidly 
grown to become a successful global brand by persistently seeking and achieving success in foreign markets. In 2011, AMOREPACIFIC was ranked as one of the global top $20 \mathrm{cos}^{-}$ metics companies the world with an yearly sales volume of about 2,500 billion won (about US $\$ 2.1$ billion) (see Table 1). It also became one of the fastest growing companies out of all other top ranked competitors. According to the Beauty Inc. Top 100 announced in 2011 by Women's Wear Daily, for example, AMOREPACIFIC's sales grew by $21.3 \%$ while the sales volume of Chanel, L'Oreal increased by $18 \%$ and $11.6 \%$, respectively. This phenomenal growth gave AMOREPACIFIC the global spotlight it currently receives. In addition, sales of Amorepacific in 2011 grew by $22.7 \%$ compared to sales in 2010. Therefore, it is not surprising that many business leaders and academics are curious how AMOREPACIFIC pulled such a feat.

This great success of AMOREPACIFIC is noteworthy since it is very rare for companies of a young and developing nation such as South Korea to make one's mark at the global stage, especially in the cosmetic industry where the country of the product's origin often plays a critical role. Moreover, what truly sets apart the global success of AMOREPACIFIC from others is how AMOREPACIPIC achieved such success using its foresight and sensational marketing. While domestic competitors chose to succeed in foreign niche markets such as those in South-East Asia, AMOREPACIFIC challenged the ultra-competitive French and American markets. AMOREPACIFIC saw that the success in France and US would be seminal

〈Table 1〉 Rank of Cosmetic Enterprises in the World (Announced in 2011)

\begin{tabular}{ccccc}
\hline Rank & Company & Sales(M USD) & Growth Rate(\%) & Nationality \\
\hline 1 & LOreal & 25,890 & 11.6 & France \\
2 & P\&G & 19,570 & 5.2 & United States \\
3 & Unilever & 16,980 & 16.2 & United Kingdom \\
4 & Estee Lauder & 8,290 & 10.6 & United States \\
5 & Shiseido & 7,750 & 6.4 & Japan \\
10 & Chanel & 4,440 & 18 & France \\
16 & AMOREPACIFIC & 2,150 & 21.3 & Korea \\
22 & ORBIS & 1,600 & 2.5 & Japan \\
25 & Elizabeth Arden & 1.410 & 7.6 & United States \\
26 & CLARINS & 1,380 & 11.1 & France \\
31 & LOCCITANTE & 976 & 23.1 & France \\
34 & LG Household \& Health Care & 887 & 10.9 & Korea \\
40 & Sisley & 673 & 10.5 & France \\
\hline
\end{tabular}

* Source: Women's Wear Daily 
in the expansion to other European and American markets in the future.

Lolita Lempicka is a perfume brand that was first introduced to France in 1997. Amorepacific is AMOREPACIFIC's namesake skincare brand that was first introduced to the US in 2003. Both Lolita Lempicka and Amorepacific overcame the intense competition and succeeded in France and US market, respectively, by not just following the market trend but by foreseeing the upcoming trends and preparing for opportunities in the future. Although the popular brands of AMOREPACIFIC in the Chinese and Southeast Asian markets such as Sulwhasoo, Laneige, Mamonde also contributed for AMOREPACIFIC's global success, Lolita Lempicka and Amorepacific are considered significant contributors as a bridgestone to global success.

The main objective of this case study is to analyze how AMOREPACIFIC became a globally successful cosmetic company while competing with well-known global cosmetic giants such as L'Oreal and Chanel. We focused on how AMOREPACIFIC took an unconventional approach when it launched Lolita Lempicka in France, and Amorepacific (brand) in the US. We will uncover the essence of its innovative marketing strategies that contributed to overcoming of their initial inferior status as an unknown brand from an unknown $\mathrm{COO}$ (country of origin). Through the process, very interesting lessons from the company's sensational ways of marketing will be revealed.

For this case study, we first review AMORE PACIFIC's history, its vision and dream, and its preparation that allowed them to soar. Then, we turn to the cases of how Lolita Lempicka and Amorepacific succeeded by foreseeing future opportunities and delivering sensational marketing. We will focus on marketing strategy under the critical period when AMOREPACIFIC achieved great success in France with Lolita Lempicka (between 1997 and 2004) and in the US with Amorepacific (between 2003 and 2008). Their success played a critical role as a bridgehead for AMOREPACIFIC to branch out globally. Finally, we will provide overall discussion, conclusion, and strategic implications.

\section{AMOREPACIFIC's Vision and Preparation to be a Global Cosmetics Company}

\subsection{Vision and Foresight for the Future}

AMOREPACIFIC has been envisioning itself "to be a global leading company that creates the harmonious value of health and beauty for people." The vision started in 1932 by a woman who lived in Gaesung. then a city of the northern part of Korea which is now the capital of North Korea. She raised her son and encouraged him to envision a beauty business 
that would give people healthy beauty. Her son, Suh Sung-hwan, later became the founder of AMOREPACIFIC. He learned the value of Korean beauty, the combination of health and beauty, and dreamt about pursuing business in cosmetic fields.

When AMOREPACIFIC was established in 1945 by Suh Sung-hwan, the Korean society was mostly interested in material affluence and practical value throughout the periods of the Japanese occupation and liberation from occupation. Under such circumstances, Suh's vision that emphasized harmonious value of health and beauty was too impractical and emotional to be understood at that time. The main competitor at that time was Rak Hee chemical service center, now LG living health, which focused on producing daily necessities such as toothpaste following the social needs at that time. Compared to that, what AMOREPACIFIC tried to accomplish what was maybe too ahead of its time. However, the founder and former President Suh Sung-hwan foresaw that once the economy stabilizes and develops, then people would look for emotional satisfaction. He was right.

AMOREPACIFIC's expansion strategies for overseas reflects the original vision of founder Suh Sung-hwan. He always believed that Korea beauty can appeal to consumers all over the world by sharing harmonious value of health and beauty. Current President Suh Kyung-bae, son of the founder, inherited from his father the same vision and spirit of promoting values of Korean beauty. He made a great effort to make AMOREPACIFIC a global cosmetics company with the inherited vision and spirit. His commitment on building its core competence and differentiating from other competitors started to pay off.

AMOREPACIFIC conquered the entry barriers of the global market by foreseeing the future opportunities that other competitive companies could not see and strengthening its core competence. It was normal for companies to follow what was the current trend at the time when entering a new market. However, AMO REPACIFIC took the unconventional way and created a new trend, as will be shown in detail later (Gallo 2011).

\subsection{Preparation for the Future}

The fact that AMOREPACIFIC was able to foresee what was to come next does not necessarily mean that the company was destined to be successful. It required a thorough preparation in order to realize and grab future opportunities. In order to gain trust from customers as a brand that pursues value of Korean healthy beauty, AMOREPACIFIC needed to improve their products' objective quality. Since the overseas cosmetic technology was far ahead of Korea, guaranteeing trustworthy quality of products were crucial.

Thus, AMOREPACIFIC founded the first laboratory for cosmetics in 1954, and the labo- 
ratory grew to be the biggest in East Asia. From modern standards, having a laboratory might not seem revolutionary at all for a cosmetics company. However, in the past there was no company that wanted to establish a laboratory for cosmetics at that time, thinking that a laboratory was not directly related to its profits. AMOREPACFIC's decision to invest in a research laboratory proved to be innovative and fruitful. In the laboratory, technicians analyzed foreign cosmetic products and used the information to improve AMOREPACIFIC's products. AMOREPACIFIC both upgraded the quality of the existing products and launched new cosmetics as well. As a result, the company succeeded in a series of highly popular hit products such as the $\mathrm{ABC}$ cream.

AMOREPACIFIC was also innovative in becoming the first company that partnered with foreign companies. AMOREPACIFIC's march toward the global market started from affiliation with Coty, a top French cosmetics company. With all these efforts, AMOREPACIFIC began making products with the highest quality even when compared with other top class foreign products. After that, AMOREPACIFIC built a local subsidiary not only in Japan, but also in Los Angeles to make inroads into foreign market since 1986.

Until now, AMOREPACIFIC made continuous investments in R\&D to ensure innovative technologies to prepare for the future. AMORE PACIFIC'S R\&D Investment over sales is higher than competitors' such as Shiseido's and Estee Lauder's (see Figure 1). We can guess from the figure that AMOREPACIFIC'S R\&D investment over sales is much higher than the average investment of Top 100 companies, although the detailed data is not available.

〈Figure 1〉 R\&D Investment over Sales

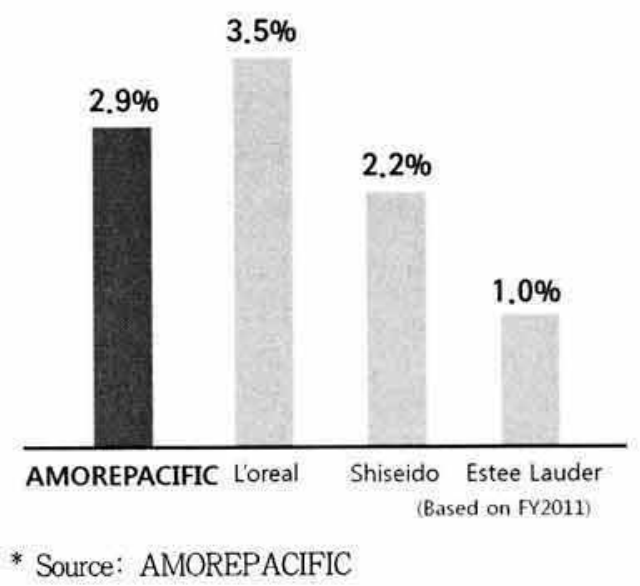

AMOREPACIFIC has an agenda of R\&D innovation that includes nurturing masters in generic technology, developing Asia-specific ingredients such as ginseng and reinforcing competency in biotechnology. These continuous efforts allowed AMOREPACIFIC to develop recognized brands in the global market.

\subsection{Challenging to Global Market}

AMOREPACIFIC decided to focus on only the cosmetic business, and sold its less lucrative, non-cosmetic businesses. AMOREPACIFIC carried out an internal organizational develop- 
ment at the same time in order to overthrow the bureaucratic spirit. As a result, AMORE PACIFIC was able to fully concentrate on its cosmetic business and establish the base for global market competition.

Afterwards, AMOREPACIFIC strengthened their core and developed new brands. In the 1990s, it launched new domestic brands such as Mamonde(1991), Laneige(1994), Iope(1996) and produced many highly popular products. Especially, Sulwhasoo(1997), the brand with influences from oriental medicine, became most popular in both domestic and foreign markets. and still is highly regarded. AMOREPACIFIC did not stop at its success in the domestic market, but diligently sought to pioneer toward foreign markets.

The saturated domestic market brought AMO REPACIFIC to a turning point. AMOREPACIFIC had to choose between staying with the domestic market, which was predicted to have sluggish sustainable growth, and entering foreign markets. On the crossroad like this, AMORE PACIFIC decided to challenge the global market, overcome difficulties, and make its vision come true. To garner the ability to fulfill their vision at the global market, AMOREPACIFIC devoted all energy to the promotion of global brands aimed at the global market: Lolita Lempicka in France and Amorepacific in the US. Finally, AMOREPACIFIC's overseas sales increased annually and the sales and market share in each entered country soared as well. In terms of overseas sales, AMOREPACIFIC's level of accomplishment is rare as it almost doubled overseas sales within 5 years, from $176.900 \mathrm{M}$ Won (about USD 147M) in 2007 to $327,200 \mathrm{M}$ Won (about USD 273M) in 2011 (see Figure 2).

As shown in figure 3 , AMOREPACIFIC successfully entered the global market with an emphasis in the foreign markets of France,

〈Figure 2〉 Global Sales of AMOREPACIFIC (2007 2011)

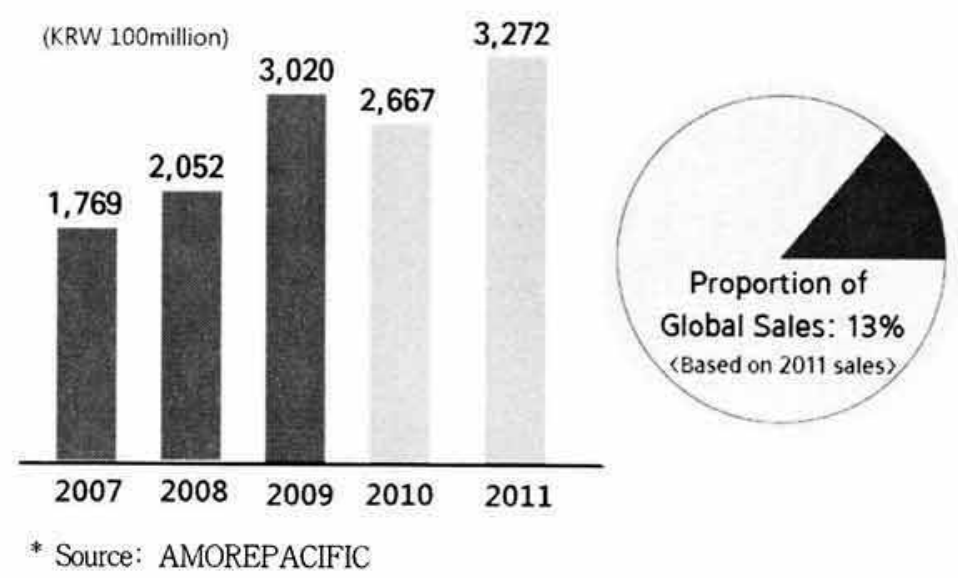

How AMOREPACIFIC Became a Globally Successful Cosmetic Company through Unconventional but Sensational Marketing? 101 
China and USA(see Figure3).

Since its foundation, AMOREPACIFIC has developed the brand essence, "A global corporation which creates balanced value of health and beauty," and tried hard to prove it in the global market. This success of AMOREPACIFIC is noteworthy since it was not easy to succeed for a company from Korea, especially in a cosmetic industry where country of product origin is very important. Moreover, what makes the global success of AMOREPACIFIC more distinct and special is how AMOREPACIFIC achieved success in the most competitive countries fighting against foreign cosmetic Goliaths. AMOREPACIFIC challenged the French market with Lolita Lempicka and the U.S. market with Amorepacific. Although France and U.S. both have tough markets, AMOREPACIFIC thought that the success in France and U.S. would have a seminal impact when it expands to other Europe and U.S. markets in the future. They were right. The success of Lolita Lempicka and Amorepacific played a critical role as a bridgestone for AMOREPACIFIC to further expand to other overseas market.

Considering the importance of Lolita Lempicka and Amorepacific in the global success of AMOREPACIFIC, this case study focused on how they achieved success in intensely competitive markets like those in France and the U.S. We now focus on the cases of Lolita Lempicka and Amorepacific. Since the case of Lolita Lempicka has been covered in many previous studies, this study reviewed the case of Amorepacific with more detail.

〈Figure 3〉 Current State of Major Businesses in Major Global Markets

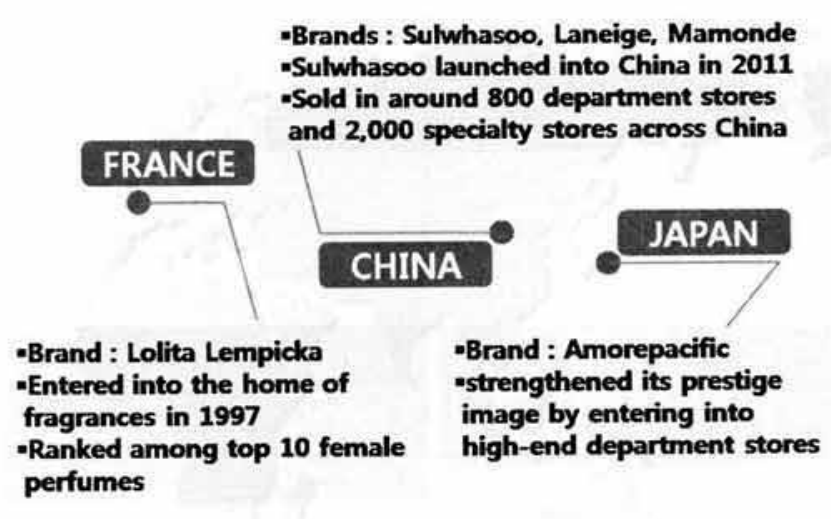

\section{USA}

-Brand : Amorepacific, Sulwhasoo

-Established the foundation for global growth by entering into the US market -Enhanced the awareness by launching the company's namesake brand Amorepacific to high-end department stores

-Strengthened the prestige image by Gallery \& Spa, a flagship store in New York

\footnotetext{
* Source: AMOREPACIFIC
} 


\section{How Did Lolita Lempicka Captivate France with Fragrance?}

Lolita Lempicka is a perfume brand that AMOREPACIFIC created for the French market and is currently being sold in over 80 countries. It is named after a French fashion designer, Lolita Lempicka. Lolita Lempicka brought a new sensation of 'ladyishness' in the French perfume market at a time when unisex products were the dominant trend. It was in 1997 when Lolita Lempicka was launched in France for the first time. It was almost a miracle for the new brand to gain $1 \%$ market share in France, within a year after its release. Lolita Lempicka's growth is highly remarkable considering that Chanel, one of the biggest cosmetics companies, took 10 years to gain its
$4 \%$ market share. The rise of Lolita Lempicka continued only at a faster rate than before. 'Le Monde', the most subscribed daily newspaper in France, gave positive reviews on Lolita Lempicka products, and Lolita Lempicka was even awarded 'Best French and European perfume' in the FiFi Award for Women's Fragrance from the FiFi Foundation. Consequently, soon the market share of Lolita Lempicka more than doubled to $2.8 \%$ in 2004, and Lolita Lempicka was ranked $4^{\text {th }}$ in the French perfume market (see Figure4).

Also a recent France survey shows that Lolita Lempicka is one of the top seven most popular brands in the women's perfume market in France (meuilleur-top.com, 2012). The market share of Lolita Lempicka is currently higher than those of the top luxury companies such as Dior's Miss Dior, and Guerlain, Lancome.

How could such a small cosmetics company

〈Figure 4〉 Market Share (\%) of Lolita Lempicka in France (1997 2004)

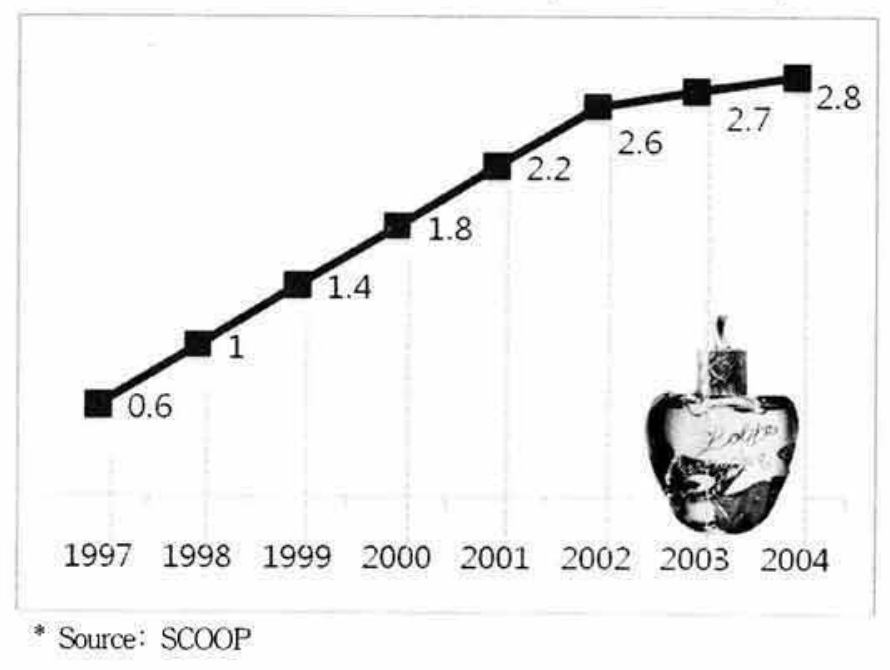

How AMOREPACIFIC Became a Globally Successful Cosmetic Company through Unconventional but Sensational Marketing? 103 
from East Asia achieve such great success at the center of the world's cosmetics market in France? We will focus on Lolita Lempicka's foresight and differentiation strategy in the time period between 1997 and 2004, since the time period was considered the most critical for not only achieving great success in France but also building the power and momentum for global market.

\subsection{Lolita Lempicka's Foresight for Femininity and Successful Entry into French Market}

Unlike other Asian cosmetic companies, AMO REPACIFIC challenged the French market, which is one of the most competitive cosmetics markets in the world. Considering the characteristics of the cosmetics industry in which the country of product origin is very important, it did not seem easy for AMOREPACIFIC as a Korean cosmetic company to succeed in France. However, AMOREPACIFIC thought that success in France would prove to be seminal to future success in other European and US markets. AMOREPACIFIC had already experienced failure before the launch of Lolita Lempicka when it had entered the market in France previously with basic cosmetics brands, 'Soon' and 'Lirikos.' This bitter experience taught AMOREPACIFIC an unforgettable lesson for Lolita Lempicka. AMOREPACIFIC learned that simply following the current market trend, even those created by highly acclaimed brands like those in France, is ineffective.

To prevent itself from making the same mistake, AMOREPACIFIC adopted an innovative way with a focus on its core values. For this end, AMOREPACIFIC tried to identify future opportunities hidden in the trend and the desires of the people and seize them. At that specific time in France, fashion that combines masculinity and femininity, the unisexual trend, was popular. The same was true for perfume: unisexual odor was most popular in the French perfume market. However, Lolita Lempicka did not follow the then-popular unisexual trend as it had learned from past experience. Lolita Lempicka believed that most woman hold a passion for ladyishness and foresaw that they will desire to express femininity. Accordingly, Lolita Lempicka emphasized femininity with its products. It turned out that the foresight was correct indeed. French women started to express their ladyishness using the Lolita Lempika perfume, and it spread quickly throughout France.

Now, we examine how Lolita Lempicka executed its innovative marketing in France.

\subsection{Marketing Strategies of Lolita Lempicka}

\subsubsection{Product strategy}

In 1997, when Lolita Lempicka was released, general trends were minimalism and unisexuality. 
Meanwhile, details that emphasized ladyishness such as romantic scents and elegant containers were very successful and earned favorable responses from French customers. Many French women desired to return to "ladyishness' through perfume, and Lolita Lempicka served well.

Lolita Lempicka tried to satisfy consumer needs by emphasizing ladyishness, not unisexuality, in visual aspects as well. In order to emphasize ladyishness, Lolita Lempicka hired talented designers and staffs from local while other companies usually send their employees to subsidiary from home countries. Lolita Lempicka invited Catherine Dauphin, who was working for Christian Dior to its local subsidiary and asked her to accent the ladyish image through creation of ladyish perfume containers. Catherine Dauphin collaborated with the best partners in order to complete the overall ladyish concept of Lolita Lempicka.

At that time, almost every perfume product had a neatly square-shaped container, but Lolita Lempicka chose to use an unconventional round shape container reminiscent of an apple for its perfume products. The round and spherical shape of containers symbolized ladyishness and were visually far more feminine than angular shapes of ordinary perfume. In addition to the ladyishness promoted through the roundshape of the perfume containers, the apple-like structure served as a biblical allusion to the forbidden apple associated with Eve, the first woman. The body of the container was de- signed like an apple and the nozzle like an apple stalk so to resemble pretty apple on the dressing table. This container design instantly grabbed women's attention and interest.

\subsubsection{Advertising strategy}

Lolita Lempicka also tried to emphasize ladyishness and promote this character in advertisements. While other perfume brands presented just their products, Lolita Lempicka used female models in a dreamlike setting and mood to appeal to consumers, especially by emphasizing ladyishness. In one of Lolita Lempicka's advertisements, a female model with elegant. feminine clothes and flower in her hair is resting in a mystical environment(see Figure5).

In another advertisement, viewers can spot a female model that resembles a mythical being like the Mermaid swimming toward the Lolita Lempicka perfume. This advertisement concept highlights Lolita Lempicka's ladyishness and fantastical qualities. Furthermore, toward men who may often purchase perfumes as presents to women, the ladyish visual of advertisements provided more sex appeal than any other advertisement of other perfume brands. Consequently, Lolita Lempicka's advertising was very successful and increased market share and sales despite heading against the unisexual trend. 
〈Figure 5〉 Advertisement of Lolita Lempicka

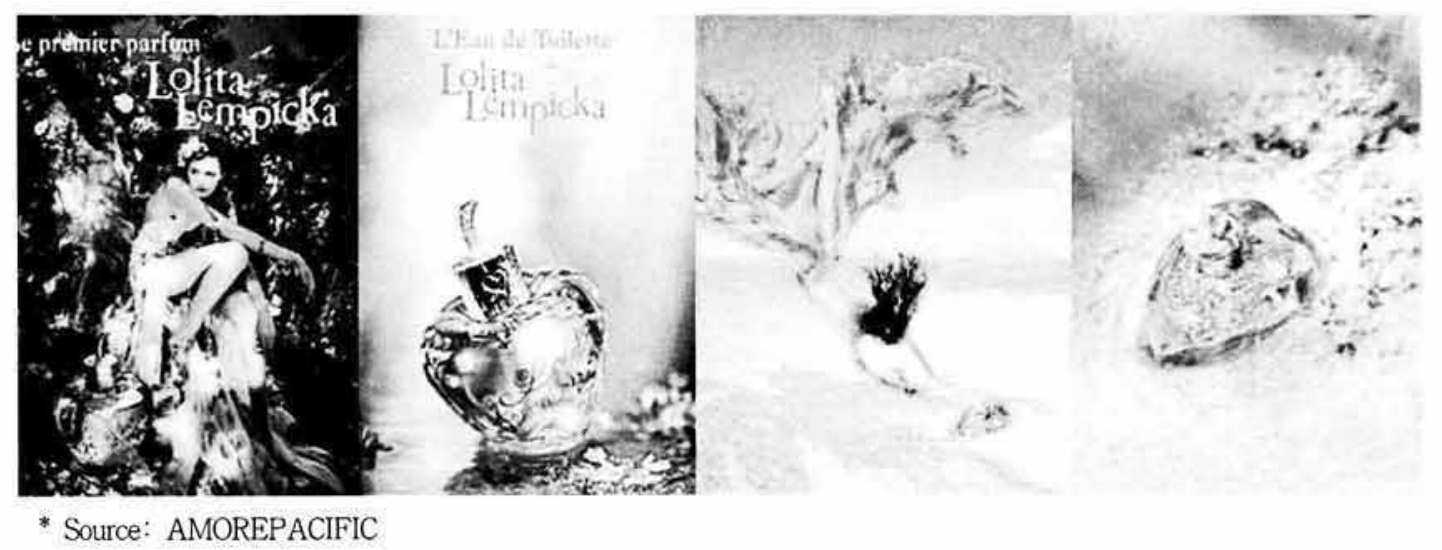

\subsubsection{Promotion strategy}

Lolita Lempicka did not limit marketing strategies to its own brand, but tried to advertise through collaboration with other brands. In 2008, Lolita Lempicka and Samsung co-designed a cell phone. SAMSUNG U600, which emphasized feminine design and contributed to Lolita Lempicka's ladyish image. A unique and unconventional purple color for mobile phones covered the exterior of the phone while the screen's background image featured Lolita Lempicka's signature playful, sexy, and mythical female. Both inside and out, U600 became a product that emotionally connected with female consumers. This collaboration with Samsung allowed the production of a phone that exudes the same kind of ladyishness expressed by their appleshaped container, sensuous scent with dreamlike Lolita Lempicka' mood, and romantic purple color, flower, and butterfly design(see Figure6).
〈Figure 6〉 Samsung Cell Phone Emphasized Ladyishness in 2008
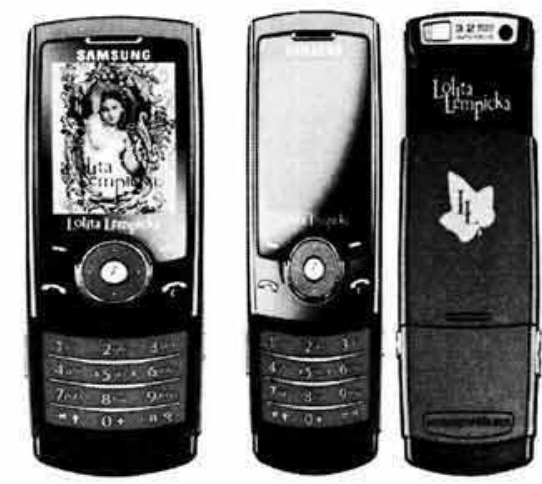

Amorepacific is a company's namesake flagship brand which was first introduced to US market in 2003. Amorepacific pioneered the new trend of clean and healthy skin to US market 
when tone cosmetic was very popular. Amorepacific continued to promote its prestigious brand image and kept growing since it first launched its product line at Bergdorf Goodman in the US, one of the most luxurious department stores in the world. Sales of Amorepacific in 2003 were 97,000 USD and grew by about 90 times to 9,051,000 USD in 2011 (See Table3)

This was an unprecedented event in the history of Korean cosmetics industry where for the first time a Korean cosmetics brand launched its products at a top-scale luxurious department store in the US. Afterwards. Amorepacific enhanced customer awareness and strengthened its prestigious image by opening its flagship stores. Amorepacific Beauty Gallery\&Spa in Soho, New York. In 2010, one of Amorepacific products, Time Response Crème, was chosen as 2010 Neiman Marcus Beauty Award- Top 5 Choice.

How did Amorepacific, an unknown East Asian cosmetic company, become a globally successful prestige brand that started a new trend in the US market?

\subsection{Amorepacific's Foresight for Well-being Trend}

With its success in France, the Mecca of the world's cosmetics industry. AMOREPACIFIC further expanded to the US market. The US market is very important for the global beauty industry because of the strong influences
Hollywood stars yield on global trends and also New York being the center of fashion industry. When Amorepacific tried to enter into the US market, the worldwide-known cosmetic companies such as L'Oreal and Chanel massively produced tone cosmetics, which were extremely popular among US customers. Tone cosmetics fulfilled the desire of users to cover their facial blemishes such as freckles. However, Amorepacific did not just follow the current trend of tone products as Lolita Lempicka did not simply follow the currently popular trend. Amorepacific foresaw that the well-being syndrome will change the cosmetic industry, and that there would be a future demand for clean and healthy skin.

The US market size for skincare has been increasing (see Table 2). This can be interpreted as a result of consumers preferring basic skin care products over color make-up products due to increased concern over skin health. AMO REPACIFIC foresaw this increase in concern over skin health and well-being. Thus. Amorepacific emphasized the beauty of clean and healthy skin with its skin care products.

The results were as successful as in France. The well-being syndrome bloomed, and US customers started to pay attention to oriental organic methods for clean and healthy skin. Further, people understood that it is more healthy and beautiful to protect the natural healthiness of their skin than to cover the freckles on their faces. Consequently, Amorepacific deepened its 
〈Table 2〉 Types of Cosmetic Market in US

(Unit: million USD)

\begin{tabular}{ccccccc}
\hline & 2007 & 2008 & 2009 & \multicolumn{2}{c}{2010} & CAGR(\%) \\
\hline & & & \multicolumn{5}{c}{ Market Size } & Ratio \\
\hline Skincare & 8,040 & 8,290 & 8,496 & 8,784 & 25.1 & 3.0 \\
Haircare & 7,507 & 7,452 & 7,352 & 7,232 & 20.6 & -1.2 \\
Personal hygiene & 5,888 & 6,049 & 6,221 & 6,406 & 18.3 & 2.9 \\
Make-up & 6,068 & 6,085 & 6,105 & 6,169 & 17.6 & 0.6 \\
Fragrances & 5,711 & 5,526 & 5,356 & 5,294 & 15.1 & -2.5 \\
Male Toiletries & 798 & 755 & 742 & 738 & 2.1 & -2.6 \\
Baby personal care & 410 & 421 & 413 & 408 & 1.2 & -0.1 \\
Totals & 34,421 & 34,577 & 34,684 & 35,031 & 100.0 & \\
\hline
\end{tabular}

* Source: Datamonitor Personal Care Market Data, 2011

prestige image as a premium skincare brand.

Now, let's turn to the major facets of Amorepacific's positioning and marketing strategies.

\subsection{Launching and High-end Positioning strategy of Amorepacific}

With its flagship store in tandem. Amorepacific launched its product line at Bergdorf Goodman in the US, one of the most luxurious department stores in the world, to promote its prestigious brand image. Amorepacific tried to leverage established luxury image of top department store into its brand image. Amorepacific expanded from the Bergdorf Goodman store to more than 30 top department stores in the current year. In addition to Bergdorf Goodman, Amorepacific opened the flagship store called Amorepacific Beauty Gallery \& Spa in Soho, New York in July at the same time. Soho area in New York is very well-known area for its fashionable and luxurious image. Thus, both the luxury department store and the Soho area helped Amorepacific to position itself as a high-end, prestige brand in the minds of the US consumers.

\subsection{Marketing Strategies of Amorepacific}

In order to strengthen high-end positioning, Amorepacific came up with differentiated marketing (or ' $4 \mathrm{P}$ ') strategies. Details of marketing strategies are described as follows.

\subsubsection{Product and price strategy}

Products of Amorepacific were mainly for clean and healthy skin. Raw materials for Amorepacific products are botanical ingredients such as red ginseng, bamboo sap, extracts from green tea, and so on. These ingredients were directly imported from farms in Korea such as Jeju Island 
or local farms. In addition, Amorepacific developed its own technology to produce high quality products. The ingredients of products were encapsulated in nanoparticles to ensure quick and deep absorption by using nano delivery technologies.

Products of the Amorepacific line were comprised of skin cleansers, toners, lotions, and serums. As Amorepacific produced high quality products, prices of Amorepacific products were relatively high. For example, Time Response Renewal Cream has a price range of $\$ 400$ $\$ 500$. Design of product package is very simple, but, reflects an image of Eastern women's mysterious beauty in its simple package (see Figure 7).

\subsubsection{Channel strategy emphasizing experiential marketing}

After Amorepacific opened its first store in the luxurious department store, it expanded very fast. Amorepacific had only 2 stores including Amorepacific Beauty Gallery \& Spa when it launched in 2003. However, the number of stores increased from 2 in 2003 to 139 in 2011. More details about how it expanded over time in the US in terms of the number of stores and sales are shown in Table 3.

In addition to fast increase in number of stores, Amorepacific provided differentiated experiential opportunities to customers through its flagship store. Amorepacific Beauty Gallery \& Spa in New York's Soho was different from

〈Figure 7〉 Packages of Amorepacific Products

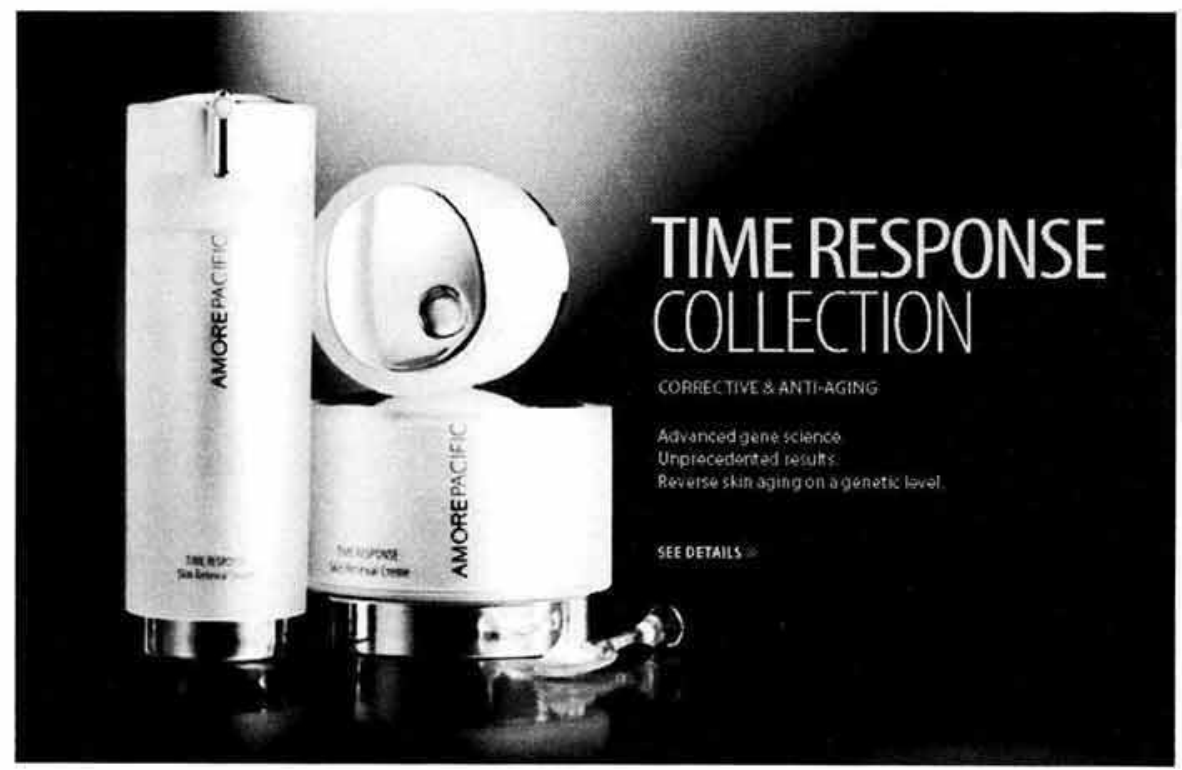

* Source: AMOREPACIFIC 
〈Table 3〉 A. The Number of Amorepacific's Stores in the USA

\begin{tabular}{ccccccccccc}
\hline Channel & OPEN & 2003 & 2004 & 2005 & 2006 & 2007 & 2008 & 2009 & 2010 & 2011 \\
\hline Flagship & Sep 2003 & 1 & 1 & 1 & 1 & 1 & 1 & 1 & 1 & 1 \\
Bergdorf Goodman & Sep 2003 & 1 & 1 & 1 & 1 & 1 & 1 & 1 & 1 & 1 \\
Nieman Marcus & April 2005 & & & 9 & 23 & 31 & 31 & 27 & 9 & 26 \\
Sephora & Sep 2009 & & & & & & & 21 & 84 & 102 \\
Nordstrom & March 2012 & & & & & & & & & \\
Others & & & & & & & 5 & 9 & 9 & 5 \\
Total & & 2 & 2 & 11 & 25 & 33 & 38 & 59 & 121 & 139 \\
\hline
\end{tabular}

B. The Sales of Amorepacific in the USA (unit: K USD)

\begin{tabular}{ccccccccccc}
\hline Channel & OPEN & 2003 & 2004 & 2005 & 2006 & 2007 & 2008 & 2009 & 2010 & 2011 \\
\hline Flagship & Sep 2003 & 52 & 546 & 664 & 737 & 630 & 706 & 546 & 664 & 737 \\
Bergdorf Goodman & Sep 2003 & 45 & 262 & 413 & 488 & 595 & 613 & 262 & 413 & 488 \\
Nieman Marcus & April 2005 & & & 631 & 2.437 & 3,769 & 4350 & 3.555 & 631 & 2,437 \\
Sephora & Sep 2009 & & & & & & & 422 & 1,174 & 3,220 \\
Nordstrom & March 2012 & & & & & & & & & \\
Others & & & & & & & 52 & 370 & 471 & 535 \\
Total & & 97 & 808 & 1,708 & 3,662 & 4,994 & 5720 & 5371 & 6,198 & 9,051 \\
\hline
\end{tabular}

*Source: AMOREPACIFIC

the conventional distribution channel which only sells products. This new store provided experiential rooms for customers while promoting the oriental well-being culture. Amorepacific displayed its products at the Amorepacific Gallery \& Spa and provided opportunities to sample for the customers. The spa also provided high quality service to customers. Amorepacific Beauty Gallery \& Spa used its own products while providing oriental-style, high-quality therapy service to customers who were tired from daily work and desired refreshment. The spa service made them relax and enjoy the comfort. The intention was to express the true beauty, the beauty inside, as opposed to the beauty outside, colorful but artificial look. The real beauty could be achieved through inner relaxation offered the spa service in the store.

For this reason, Amorepacific spa's interior was also designed using environmental friendly materials to emphasize the healthy beauty and the inner well-being. Wooden ceilings which implicates the energy erupted from the trees, spa booth using the passionate red color of red Ginseng, all contributed to the luxurious and inner-relaxing mood of the healthy spa. The intention of Amorepacific was to make the customers feel the excellence of their products 
〈Figure 8> AMOREPACIFIC Beauty Gallery \& Spa in Soho, New York

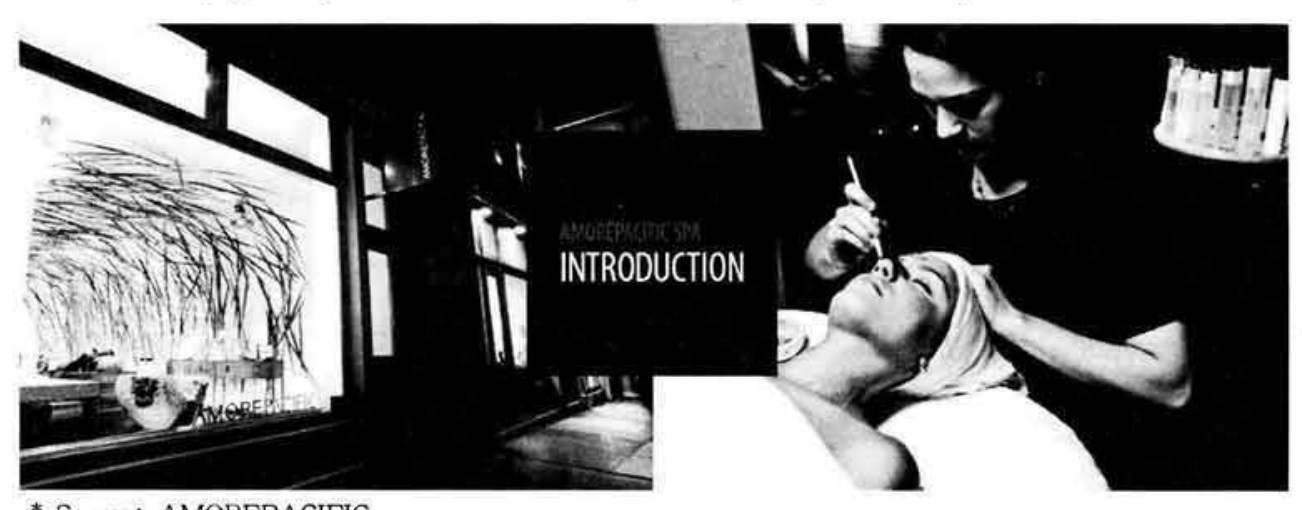

* Source: AMOREPACIFIC

and high quality of the spa so that they would share the experiences with their friends. The strategy was in line with the theory that explains the important role of the customer experiences in evaluating products (Lee et al. 2004). According to the theory, the customer who experienced a product tends to purchase the same product again.

This experiential marketing strategy showed Amorepacific's confidence in its product quality. It was very successful because customers who once experienced Amorepacific products were very satisfied with its high quality and purchased the products again and again.

\subsubsection{IMC strategy through viral marketing}

Since experiential marketing strategy was successful, customers' satisfaction of Amorepacific Beauty Gallery \& Spa was shared enthusiastically with friends and others. Word-of-Mouth (WOM) became more important in marketing since people then had more opportunities to give their personal opinions due to the development of online. Therefore, Amorepacific tried to spread good words about it by using viral marketing strategy. Instead of spending lots of money on an expensive ad campaign, the company gave out samples of its products to magazine editors. As a result, Amorepacific's name was getting more popular.

Furthermore, Amorepacific enhanced customer awareness through paparazzi shots of Hollywood celebrities holding Amorepacific products. Female celebrities covering their faces with shopping bags printed Amorepacific gave Amorepacific an image that its products are used by beautiful celebrities, and this spread through US customers rapidly. In addition, the famous Hollywood celebrity Sienna Miller was recently picked for Amorepacific advertising model(see Figure 9). As Sienna Miller had shared that she personally prefers Amorepacific products through the media before she became the model of 
〈Figure 9〉 Hollywood Celebrity, Sienna Miller with AMOREPACIFIC
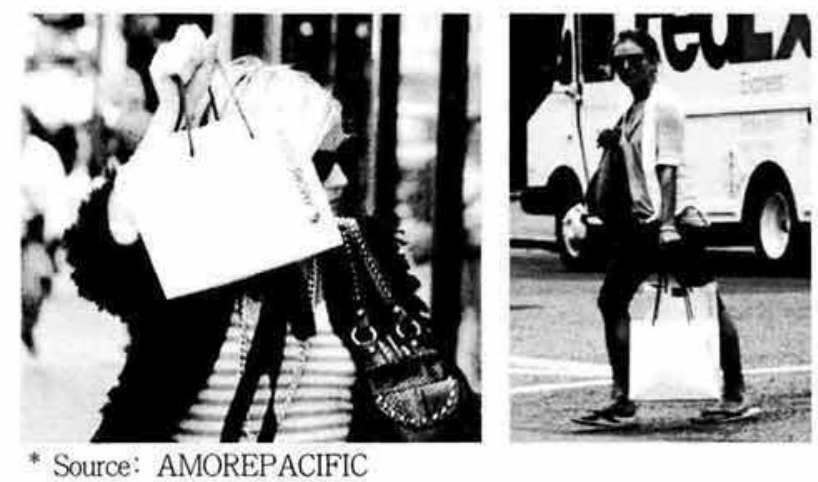

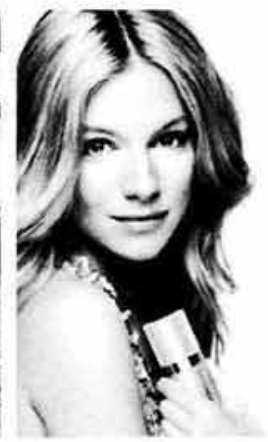

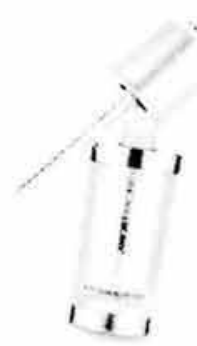

Amorepacific, it gave credibility to her advertisements and spread positive words of mouth about Amorepacific.

\section{Overall Discussion, Conclusion and Implications}

This case study reviewed how AMOREPACIFIC became a global cosmetic company through building key brands such as Lolita Lempicka and Amorepaficic, among others. This study also analyzed how AMOREPACIFIC employed innovative marketing to realize its vision and dream of becoming a top global company and sharing Korean beauty with the rest of the world.

What makes AMOREPACIFIC's global success noteworthy and unusual is that AMORE PACIFIC first challenged the France and the US market, where competition level is the toughest, in order to make a base for later expansions to other foreign market. Considering that the country of product origin is very important in the cosmetics world, Lolita Lempicka and Amorepacific fought an uphill battle for their success and played a significant role for AMOREPACIFIC in becoming a global leader in cosmetics.

The main success factor of Lolita Lempicka and Amorepacific can be attributed to foresight for future opportunities without losing focus on its core character and values. This global success was possible because of the vision and spirit of AMOREPACIFIC, "To become a global leading company that creates the harmonious value of health and beauty." The company has always believed in the value of Korean beauty and kept on moving forward to share it with the world as one of its slogans. "Asian Beauty Creator," highlights. The vision and spirit has led AMOREPACIFIC to focus on its core competence and not just to follow what competitors do even in toughest global markets. As the company envisioned. Lolita Lempicka and Amorepacific both did not follow the popular 
market trend at the time when they entered into the new market.

The case of AMOREPACIFIC's success in the global markets can give valuable lessons to companies that want to extend their businesses to foreign countries and ultimately become global. One such lesson is the importance of building a successful pioneer brand in a powerful bridgehead market. While domestic competitors first entered into less competitive market such as South-East Asia area, AMOREPACIFIC challenged the toughest markets such as the French or US markets where the incumbent companies waged the most intensive and severe battles against Lolita Lempick and Amorepacific. Through the success in France and US market, however, AMOREPACIFIC built a powerful base for its successful global expansion.

The other valuable lesson is the importance of foresight to uncover great opportunities hidden behind the trends without losing focus on its core character and values. Lolita Lempicka and Amorepacific showed the excellence in foresight competition, which led them to succeed against the intense competition from Goliath companies. Lolita Lempicka foresaw the new trend of ladyishness when unisexual trend was dominant in the French market. Amorepacific foresaw the well-being syndrome for clean and healthy skin when the tone cosmetics for covering freckles were popular in the American market. Both Lolita Lempicka and Amorepacific created new market segment and took the lead by foreseeing future opportunity hidden under the paradigm shift (see figure 10). If Lolita Lempicka and Amorepacific had just followed the popular market trend at the time, they would have never succeeded.

Jong-yong Yun, who as the CEO of Samsung directed its own tremendous global success, also pointed out that the success of company depends on how well it prepares for a paradigm shift in the future. That is exactly what Samsung did for its success. In order to overcome the supremacy of SONY in the mid-90s, Samsung excelled in foresight. uncovering the

〈Figure 10〉 Catch-up Strategy of Late-movers through Creating New Market Segment

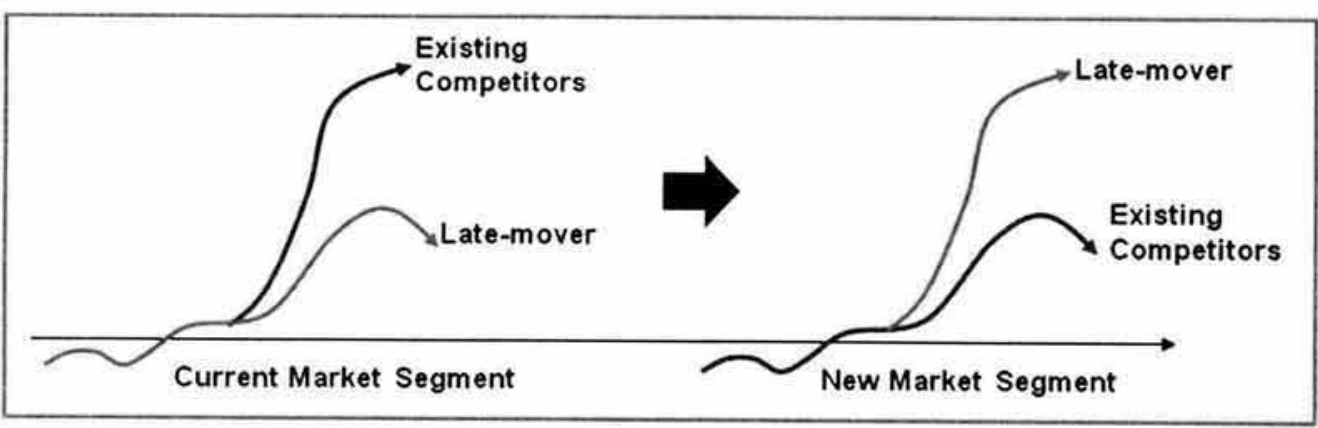

* Source: Kim(2005), Marketing for the Future 
opportunities hidden behind the paradigm shift that would change systems from analog to digital, wire to mobile, etc. (Kim, 2005, 2011). Foreseeing and preparing for paradigm shift is critically important especially in these days when the business environment is very unpredictable and rapidly altered. Therefore, we recommend that AMOREPACIFIC continue to focus on the next paradigm shift as it did in order to become more successful global leading cosmetic company.

Although this case study reviewed only Lolita Lempicka and Amorepacific due to its seminal role in AMOREPACIPIC's global expansion, there are many other AMOREPACIFIC brands such as Sulwhasoo, Laneige, Mamonde and so on which are widely successful today. Since these brands significantly contribute to AMOREPACIFIC's global success today, future study should address how these brands performed and succeeded the global market and what their roles should be for the future of AMOREPACIFIC.

〈Received September 24. 2012〉

〈Revised December 5. 2012〉

〈Accepted December 12. 2012〉

\section{References}

Aaker, David (2004), "Leveraging the Corporate Brand," California Management Review, 46(3), 6-18.
Aaker, Jennifer, Susan Fournier, and S. Adam Brasel (2004), "When Good Brands Do Bad," Journal of Consumer Research, 31(1), 1-16. AMOREPACIFIC(2012), AMOREPACIFIC IR Report 2012

Choi, Jin-a (2008) "Globalization of AmorePacific Corp: Dynamic Capability Building Approach," Social Science Research, 13, 113138.

Christensen, Clayton M. Scott Anthony and Eric Roth (2004), Seeing What's Next?: Using Theories of Innovation to Predict Industry Change. MA: Harvard Business School Press.

Datamonitor (2011), "Personal Care Market Data," (accessed March18, 2011), [available at http://www.datamonitor.com]

Gallo, Carmine (2011), The Innovation Secret of Steve Jobs, McGrow Hill.

Ghemawat, Pankaj, Carin-Isabel Knoop and David Kiron (2005), “Amorepacific: From Local to Global Beauty," Harvard Business Review, September 26.

Lee, HanJoon, Jong-Chul Park and Hye-Young Oh (2012), "The Use of Country of Origin Stereotypes: The Role of Product Specificity and Consumer Motivation," Asia Marketing Journal,13(4), 77-103.

Harvard Business Review (1999), Harvard Business Review on Entrepreneurship. Harvard Business Review Press.

Hong, Sung Tai and Eun A Park (2005), "Comparison of Female Consumers' Purchasing 
Behavior by Lifestyle Types: In the Case of Cosmetics," Journal of Korean Marketing Association, 20(1), 55-89.

Jeong. Teaseon (2012), "From Korea to the World: Even Hollywood Celebrities Fell in Love with Korean Cosmetics"(accessed April 17, 2012), [available at http://www.edaily. co.kr].

Jim, Collins (2001), Good to Great, New York: Harper Business Publisher.

Kim, Chung K. (2005), Marketing for the Future, Kyobo Books.

Kim, Chung K. (2011), Preparer Your Wing. 1000 Years' Treasure.

Kim, Chung K., Greg Pratt, Mina Jun, Miyea Kim and Jeongsoo Han(2012), "Searching for the Korean Ways of Making a Dent in the Universe: Analysis of Top Winning Korean Brands," in How Korean Brands Saar all over the World, Chung K. Kim, Greg Pratt, Mina Jun, Miyea Kim and Jeongsoo Han, eds., The 1000 Years' Treasure, 1-8. Kim, Chung K., Mina Jun, Jeongsoo Han, Miyea Kim, Jungung Park and Jushua J. Kim (2012), "A Case Study of Shinsegae E-mart: How E-mart Became the Number one Distribution Company even against Economic Crisis and the Entry of Walmart?," Asia Marketing Journal, 14(3), 7-26.

Kim, Gabsik (2006), "Power Brand: Fragrance of AMORE Shakes the Paris," (accessed September4, 2006). [available at http:// news.donga.com].
Kim, Jooheon (2003), "Global Strategies of AMOREPACIFIC," International Business Studies, 14(2), 55-82.

Korea Health Industry Development Institute (2011), Analysis Report of Cosmetic Industry 2011. December

Kozinets, Robert V., Kristine De Valck, Andrea C. Wojnicki and Sara J.S. Wilner (2010), "Networked Narratives: Understanding Wordof-Mouth Marketing in Online Communities," Journal of Marketing, 74(2), 1-52.

Leenders, Michael R, and James A. Erskine (1989), Case Research: The Case Writing Process, $3^{\text {rd }}$ edition, School of Business Administration, University of Western Ontario. Maheswaran, Durairajand and Cathy Yi Chen (2006), "Nation Equity: Incidental Emotions in Country of Origin Effects," Journal of Consumer Research, 33(3), 370-376.

Meilleur Top (2012), "Meilleur Top 7 Des Meilleurs Parfums De Femmes Les Plus Vendus En 2011,"(accessed July 4, 2012), [available at http://www.meilleur-top.com].

Ofek, Elie and Kerry Herman (2007), "Amorefacific," Harvard Business Review, April 6. Park, Soyeon (2012), Sienna Miller, Picked for Amorepacific Model, (March 29, 2012), [available at http://www. Asiae.co.kr/news] Perfume Shrine (2012), Top 20 Best-Selling fragrances for women in France 2011, Friday, March 2, http://perfumeshrine.blogspot.kr. Prahalad, C. K. and Gary Hamel (1990), "The Core Competence of the Corporation," Harvard 
Business Review, 68(3), 79-91.

Shim, Heejeong (2012), "We Make Global Korea more quickly: AMOREPACIPIC Group," (accessed June 25, 2012), [available at http://economy.hankooki.com].

Yoon, Sung Joon, HyoungJu Lee and Young Mi Kim (2011), "A Study on the Relation- ships among Sought Benefits, Purchase Experiences, and Brand Relationship in Case of Cosmetics," Asia Marketing Journal, 13 (2), 1-26.

Women's Wear Daily (2011), WWD Beauty Report 2011, (accessed August, 2011) [available at http://www.wwd.com]. 